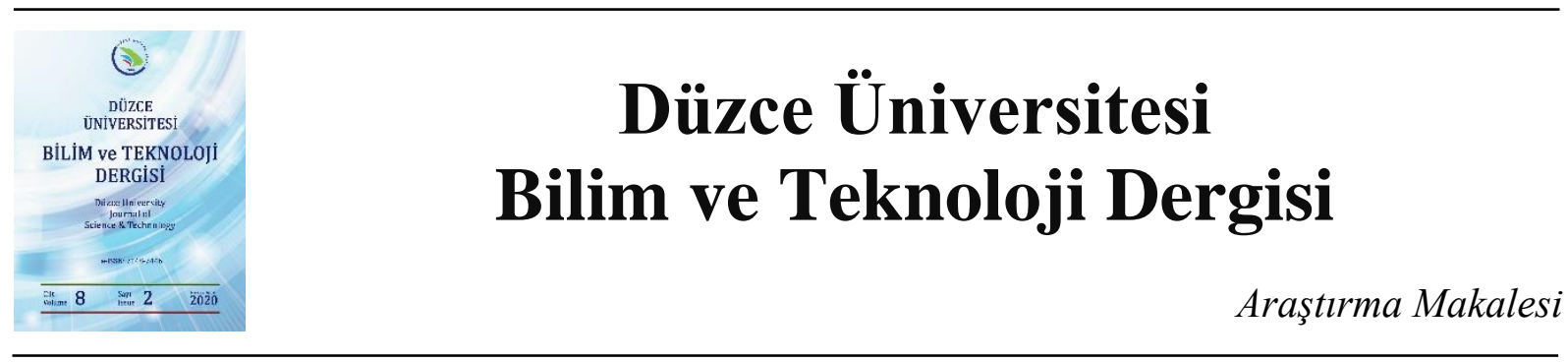

\section{Örgüt Kültürünün Çalışanlarda İnovatif Düşünce Geliştirme İş Tatmini ve Örgüt Bağlılığına Etkisi (Lif Levha Sanayi Örneği)}

\author{
Kadri Cemil AKYÜZ a,* (D) İbrahim YILDIRIM ${ }^{\text {a, }}$ (D) Kahraman GÜRSOY ${ }^{\text {b }}$ \\ a Orman Endüstri Mühendisliği Bölümü, Orman Fakültesi, Karadeniz Teknik Üniversitesi, Trabzon, TÜRKIYYE \\ ${ }^{b}$ Orman Endüstri Yüksek Mühendisi, Ordu, TÜRKIYYE \\ * Sorumlu yazartn e-posta adresi: akyuz@ktu.edu.tr
}

DOI: 10.29130/dubited.664709

\begin{abstract}
ÖZET
İşletmelerin rekabette üstün konumda olmaları ve sahip oldukları pazar paylarını geliştirebilmeleri çalışanlarının potansiyel güçlerini açığa çıkarabilmesi ve kurumsal olarak inovatif düşünceye önem vermeleri ile yakından ilgilidir. Firmaların sahip oldukları kültürel yapı ve yönetim tarzı çalışanlar üzerinde yeniliklere katkı sağlamak, örgütüne bağlllık ve iş tatmini boyutlarında önemli bir etkiye sahip durumdadır. Bu çalışmada örgüt kültürünün çalışanlarda inovatif düşünce geliştirme, iş tatmini ve örgüt bağlılığına etkisinin belirlenmesi amaçlanmıştır. Bu amaç doğrultusunda Orman Ürünleri Sanayi Sektörünün önemli bir alt sanayi dalı konumunda olan Lif Levha Sanayi'nde uluslararası alanda geçerliliği kanıtlanmış anketler kullanılarak çalışanlar üzerinde araştırmalar yapılmıştır. Elde edilen veriler istatistiki analizlere tabi tutulmuş ve inovatif düşünce geliştirme, iş tatmini, örgüt bağlllığı ve örgüt kültürü arasında istatistiksel olarak anlamlı ve olumlu ilişkiler olduğu belirlenmiştir.
\end{abstract}

Anahtar Kelimeler: İnovatif düşünce, Işs tatmini, Örgütsel bağlllık, Örgüt kültürü

\section{The Effect of Organizational Culture on Job Satisfaction and Development of Innovative Thinking and Organizational Commutment in Employess (Fiber Plate Industry Example)}

\begin{abstract}
The superiority of enterprises in the competition and the development of their market shares are closely related to their employees' ability to unleash their potential strengths and to give importance to innovative thinking in the enterprise. The cultural structure and management style of the companies have a significant impact on the contribution of innovations on employees, loyalty to their organization and job satisfaction. The aim of this study is to determine the effect of organizational culture on the development of innovative thinking, job satisfaction and organizational commitment in employees. In line with this aim, research has been carried out on the employees using internationally proven questionnaires in Fiber Sheet Industry, which is an important subindustry branch of the Forest Products Industry Sector. The data obtained were subjected to statistical analysis and it was determined that there were statistically significant and positive relationships between innovative thinking development, job satisfaction, organizational commitment and organizational culture.
\end{abstract}

Keywords: Innovative thinking, Job satisfaction, Organizational commitment, Organizational culture 


\section{GIRIS}

Küreselleşme ve sürekli olarak değişimle beraber dünya, tek bir pazar halini almıştır. Her sektörde gerçekleşen değişimlerle birlikte dünyanın farklı bölgelerinde bulunan ve faaliyet gösteren örgütler kendilerini en iyi şekilde müşteri isteklerine yanıt verme yarışında bulmuşlardır. Örgütler arasında artan rekabet, kendilerini sürekli yenileme ve rakiplere üstünlük sağlama zorunluğuna dönüşmüş ve inovasyon ve inovatif düşünce yakından takip edilmeye başlanmıştır [1]. Özellikle global çapta son 50 sene içerisinde yaşanan ekonomik krizlerle beraber inovasyon çalışmaları artmıştır. İnovasyon üretim birimlerinin itici gücü ve gelişmenin anahtarı olarak görülmekte hem uluslararası hem de ulusal düzeyde rekabette önemli bir rol oynamaktadır [2].

Örgütsel düzeyde inovatif düşüncenin başarılı olabilmesi örgütün sahip olduğu kültürel yap1 ile yakından ilgilidir. Örgüt bünyesinde yıllara ve yönetsel bakış açısına bağlı olarak gelişen kültürel yapı gerek çalışanları yenilikçi düşünme ve uygulamaya sevk edebilmekte ve gerekse çalışanların örgütlerine bağlılıkla hareket edebilmeleri ve bu bağlamda yaptıkları işten memnuniyet duymalarına neden olabilmektedir. Bu konumda bir yönetsel bakış açısına sahip olan örgütlerin rekabet alanında ön planda yer almaları yanında sürekli yön belirleyici konumda olacakları açıktır.

Literatüre bakıldığında örgüt kültürünün inovatif düşünce geliştirme, iş tatmini ve örgütsel bağl1lık üzerine etkisini inceleyen araştırmalarda dört değişkeni ele alan az sayıda çalışma görülmektedir. Bu çalışmada Lif Levha Sanayi alanında ülkemizin köklü ve önder bir firmasında sahip olunan örgütsel kültürün çalışanlarda inovatif düşünce, örgütsel bağl1lı ve iş tatmini düzeylerinde nasıl bir etkiye sahip olduğunun belirlenmesi amaçlanmıştır.

\section{GENEL BILGILER}

\section{A. ÖRGÜT KÜLTÜRÜ}

Örgüt kültürü kavramının anlaşılması için örgüt ve kültür kavramlarının ele alınması gerekmektedir. En geniş şekliyle örgüt saptanan hedeflere ulaşmak için çalışanların çabalarının düzenlendiği yönetim fonksiyonu; teknolojik boyut, birey ve hedeflerin etkileşim içerisinde olduğu bir sistem; kendisine özgü ve kimliği belirleyen bir kültürü olan; gerçekleştirecekleri görevleri, çalışanları, aralarındaki yetkileri ve bulundukları iletişimleri içeren bir yapı şeklinde tanımlanabilmektedir [3]. Yönetim ve örgüt çalışmaları alanının kurucularından olan March örgütleri karar veren yapılar şeklinde ifade etmekte ve örgütlerin öğrendiklerini, uyum sağladıklarını, risk aldıklarını ve üyelerinin kolektif eylemlerini şekillendirdiklerini belirtmektedir $[4,5]$.

Kültür, örgütteki tüm üyelerin etkileşimi sonucunda meydana gelen ve liderlerin davranışları ile biçimlenen eylemlerin sonuçlarını kapsayan dinamik bir yapıdır. Bunun yanı sıra kültür; örgütlerde üyelerin davranışlarının biçimlenmesi, diğer üyelere yol göstermede ön plana çıkan yapılar, rutinler, roller ve normların toplamıdır. Örgüt kültürü ise örgüt ve kültür kavramlarını içerisinde bulunduran ve hem örgüt teorileri hem de yönetim bilimlerinde her geçen gün daha da önemli bir konu haline gelen bir kavramdır. Çalışanların mücadeleleri veya örgüt ikliminin sonucunda örgütlerin gelişmesiyle uygulamada hem yöneticiler hem de araştırmalar on yıllardır kültürü dikkatle incelemektedir [6]. Üst yönetim tarafından belirlenen stratejilerin örgüt genelinde benimsetilmesi ve uygulanması amaciyla önemli bir araç olarak görülen örgüt kültürü, stratejik yönetim sürecinin önemli unsurlarından biridir $[7,8]$.

Tüm bu araştırmacılar kültürün var olduğuna inanmakta ve örgüt kültürü ile ilgilenmekte; ancak örgüt kültürünü tamamlarken her biri farklı bir bakış açısından bakmaktadır. Bu nedenle de örgüt kültürünün tek ve kesin bir tanımını yapmak oldukça zor olmaktadır. Örgüt kültürü örgütsel hayatın tüm bakış açılarının merkezinde bulunan bir kültür genişlemesi şeklinde ele alınabilmektedir [9]. Diğer bir ifade 
ile örgüt kültürü örgütlerce sağlanan fikirlerin, kuralların ve davranışların toplumda bulunan bireylere ait inançlar ve değerler tarafından biçimlenmesi olarak da tanımlanmaktadır [10].

Özünde kültür olayları tüm yönüyle açıklamaya ve düzenlemeye yardımcı olan bir olgudur. Eğer kültürün dinamikleri doğru şekilde anlaşılırsa, ani ve beklenmeyen olaylar ile karşılaşıldığında çalışanlar daha sağduyulu şekilde tepki verebilmektedirler. Bu bağlam örgüt kültürü kavramı grup kültürü şeklinde de tanımlanabilmektedir [6].

\section{B. INOVASYON KAVRAMI}

Rekabet koşulları altında başarıya ulaşmak ve rakiplerine üstünlük sağlamak isteyen örgütler için inovasyon olmazsa olmaz bir olgudur. Küresel değişimin ekonomileri etkilemesi sonucunda her örgüt için öncelikli duruma kavuşan inovasyon örgütler için en önemli konulardan birisini oluşturmaktadır [11]. İnovasyon yönetimle ilgili, sosyal ve kültürel süreç ve işlemlerde yeni ve farkl1 yöntemlerin kullanılmasıdır. İnovasyon ayrıca ekonomik gelişim ve büyümede de önemlidir. İnovasyon kavramı piyasaya yeni sürülen hizmet ya da ürünün pazarlanması ya da imalatında yeni süreçlerin kullanılmasını ifade etmekte; girişimciliğin en önemli işlevlerinden birisini oluşturmaktadır. İnovasyonun yapılabilmesi için girişimcinin teknoloji, sermaye ve yeni kaynaklar koyması ve bu şekilde hizmet ve ürün konfor ve kalitesini artırması gerekmektedir [12,13, 14]. Bunlara ek olarak girişimcilik ile teknolojinin yönlendirdiği inovasyon, örgütlere sürdürülebilir rekabet üstünlüğü kazandırmada bir diğer ifadeyle firmaları rekabet ettiği firmalardan farklılaştırmada etkili olabilmektedir [15]. İnovasyon bilinen bölgenin dışına çıkmak, risk almak ve değişmek anlamlarında da kullanılmakta ve bir değişim disiplinini oluşturmaktadır [16].

İnovasyon en basit tanımı ile yeni ve yenilikçi fikirlerin katma değer yaratması olarak tanımlanmaktadır. İcat, yenilikçilik ve inovasyon kavramları genellikle birbirlerine karıştırılmaktadır. Drucker [17]'a göre inovasyon ile yenilik kavramlarının birbirleriyle karıştırılması, bir yöneticinin yapacağı en büyük hatalardan birisidir. Çünkü yenilik ve inovasyon birbirlerinden farklı kavramlardır. Kavramlar arasındaki fark değer yaratımından kaynaklanmaktadır. Aynı şekilde icat ve inovasyon kavramları da birbirleriyle aynı anlama gelmemektedir. İcat yeni veya geliştirilmiş sistem, metot ya da araç için bir model, düşünce ya da taslaktır. İnovasyon ise değer yaratma sürecini de kapsayan yeni araç, sistem, metot veya üretimlerin ekonomik anlamda kullanılmasıdır [18].

Bu durumu Yorgancılar [19], alışılmamış “yeni” bir şeyin yaratılmasına inovasyon adının verilmesi için "ekonomik değer" oluşturması gerekmektedir şeklinde belirtmektedir. Yani inovasyonun tanımlanabilmesi için "ekonomik değer" ve iktisadi değere dönülebilen bir yenilik gerekmektedir. Eğer yenilik sonucunda herhangi bir ekonomik değer elde edilmiyorsa inovasyon olarak değerlendirilememektedir. Makroekonomik ve mikroekonomik seviyede inovasyonunun önemini literatürde ilk veren Schumpeter'dir. O'na göre inovasyon;

- "Yeni bir üretim yöntemi geliştirmek"

- "Yeni bir ürün ortaya çikarmak"

- "Hammadde ya da yarı mamul sağlamak için yeni kaynaklar geliştirmek"

- "Yeni bir örgüt oluşturmak" gibi faaliyetleri kapsamaktadır [20].

\section{C. İş TATMINI}

İş tatmini en basit şekliyle bir bireyin çalıştığ çalışanların yaptıkları işe karşı duyduğu tepki olarak tanımlanmaktadır. Bireylerin iş ve iş deneyimlerini değerlendirmeleri ve bunun sonucunda ortaya çıkan olumlu duygusal ifadeleridir [21]. İş tatmini işten elde edilen sonuçlar veya iş şartlarının bireysel olarak değerlendirilmesidir. İş tatmini bireylerin iş ve kendilerine dair işle ilgili algıları ve algılarına dair duygusal tepkileridir [22]. 
İş tatmini çalışanların işleriyle ilgili doyumlarını ve duygularını ifade eden bir kavram olarak ilk defa 1920'li yıllarda kullanılmış ve 1930-40'lara gelindiğinde örgütlerde önemli bir bileşen olduğu anlaşılmıştır. İş tatmini yaşam tatminini de doğrudan etkilemekte ve bireyin ruhsal ve fiziksel sağlığıyla ilişkili olduğu için önemli kabul edilmektedir. Örgütler açısından önemi ise verimlilik ve üretkenlikle olan ilişkisinden kaynaklanmaktadır. İş tatminindeki eksiklikler sonucunda disiplin sorunları, verimlilik seviyesinde azalma ve iş yavaşlatma gibi olumsuz sonuçlar görülmektedir [23].

İş tatmini bireyin iş ortamı ve işine karşı pozitif tutum ve davranışlarıdır ve bir bireyde iş tatmininin düşük olması vereceği hizmetin kalitesini doğrudan düşürebilmektedir. Çalışanların işine dair olumlu duygular hissetmesi ve sonucunda meydana gelen olumlu sonuçlar iş tatminini ifade etmektedir. İş tatmini bireyin hem işinden hem de iş çevresinden edindiği ve rahatlamasını sağlayan duygulardan oluşmaktadır [24]. İş tatmini yükselme ve gelişme imkanlarından, sosyal çalışma şartlarından, güvenlikten, ücretten ve işten duyulan tatmindir. Hızla kaybedilebileceği gibi hızla ortaya da çıkabilmektedir [25, 26].

İş tatmini hem dışsal hem de içsel değişkenlerden oluşabilmektedir. Dışsal değişkenler genel olarak çevreyle ilişkili yöneticilerle gerçekleştirilen eylemler, çalışma ortamı, hizmet davranış ve teknikleri ve ticari anlaşmalar gibi dış yapıyı içerirken, iç değişkenler sorumluluk alma, gelişim, onaylanma ve başarı gibi işle iliş̧ili unsurları kapsamaktadır [27]. İş tatmini basit bir şekilde bireylerin işleri hakkında ne düşündüklerinin ifade edilmesidir. Bireylerin hem ruhsal hem fiziksel durumlarının hem de zihinsel ve bedensel sağlıklarının bir yansımasıdır ve oldukça önemlidir [28, 29].

\section{D. ÖRGÜTSEL BAĞLILIK}

Örgütün varlığını sürdürmesi çalışanların örgütteki varlığına bağlıdır. Çalışanlar örgüte ne denli bağlı ise örgüt de o denli güçlü olmaktadır. Örgüt, hayatını sürdürmek için çalışanların örgütten ayrılmasını önlemeye çalışmaktadır [30]. Örgütsel bağl1lık kavramı, bireyin belli bir örgüte olan bütünleşme ve özdeşleşme seviyesini anlatmaktadır [31]. Bu perspektiften bakıldığında örgütsel bağl1lığın üç temel öğesi ön plana çıkmaktadır. Buna göre bir bireyin örgütte kalmayı sürdürmedeki istekliliği, örgüt için emek harcama isteğinde olması ve örgütün hedeflerini benimsemesi ve bunlara olan güçlü inanc1 örgütsel bağlılığın göstergesidir [32].

Örgütsel bağlılık farklı araştırmacılar tarafından farklı şekillerde tanımlanmaktadır. Bu tanımlarda ortak olarak örgütsel bağl1lı bireyleri örgütlerle ilintilendiren ve bağlayan bir bağdan bahsedilmektedir [33]. Bu tanımlardan bazıları şu şekildedir:

Örgütsel bağl1lık örgütün çıkar ve hedeflerine varma yolunda harekete geçmek için oluşan içselleştirilmiş normatif baskıların tamamını temsil etmektedir [34].

Bir örgütteki sendika, müşteri, üst yönetim ve genel anlamda toplumu içine alan çoklu unsurların amaçlar ile özdeşleşme sürecidir [35].

Örgütsel bağl1lık genel olarak örgüt değerlerine inanç, sadakat ve işe katılma da dahil olmak üzere çalışanın işletmesine olan psikolojik bağlılığıdır [30].

Örgütsel bağl1lık "bireyin bir örgüt ile özdeşleşmesi ve kimlik birliğinin göreceli gücü"dür. Ayrıca çalışanın kendi çıkarlarını örgütün çıkarlarının arkasına koyması ve örgüt çıkarlarını daha üstün görmesi şeklinde tanımlanabilmektedir [36].

Örgütsel bağl1lık genel bir davranış biçimi olarak örgütün değer ve hedeflerinin kabulü ve onlara kesin bir inanç; örgüt adına yüksek düzeyde emek harcamaya gönüllü olmak ve belirli bir örgütün parçası olarak kalmaya dair güçlü bir istek şeklinde tanımlanmaktadır. Diğer bir deyişle, bu bireylerin üyesi olduğu örgüte olan bağl1lıklarıyla ilişkili bir tutum ve davranış ve örgüt üyelerinin örgütün başarılı olması ve iyi olması ile ilgili ilgilerini içeren sürekli bir süreçtir [37]. 
Tanımlardan da anlaşılacağı üzere örgütsel bağlılık genel olarak araştırmacılar tarafından örgütte paylaşılan birlikteliğin moral ve psikolojik gücü; örgüte ilişkin belirli davranışsal görevleri gerçekleştirme ve örgütsel çıkar ve amaçları benimseyerek koruma isteği üzerinden tanımlanmaktadır [38].

\section{MATERYAL VE YÖNTEM}

\section{A. MATERYAL}

Orman ürünleri sanayi sektöründe yer alan, ulusal ve uluslararası düzeyde tanınırlığı ve pazar etkinliği olan bir levha fabrikası düzeyinde gerçekleştirilen çalışma firma düzeyinde gereken çalışma izinleri alınarak tamamlanmıştır. Çalışmada firmada yer alan bölümler düzeyinde inovatif düşüncenin geliştirilmesi ve bu durumun iş tatmini ve örgütsel bağlllık üzerinde ne tür etkiler oluşturduğunun belirlenmesi amaçlanmıştır. Toplam 7 farklı üretim bölümünde yer alan 190 çalışanla gerçekleştirilen çalışmada bölümlerin sahip oldukları üretim ortamı ve çalışma şekilleri kapsamında inovatif düşünce ve iş tatmini boyutları düzeyinde sahip oldukları yapı ve farklılıkların belirlenmesine çalışılmıştır.

\section{B. YÖNTEM}

Araştırmada birincil ve ikincil veri kaynaklarından yararlanılmış olup ikincil veriler için literatürde yer alan çalışmalar incelenmiş ve uluslararası alanda geçerliliği kanıtlanmış anketlerden yararlanılarak amacımıza uygun olarak tasarlanan anket formu ile verilerin elde edilmesi sağlanmıştır. Oluşturulan anket formu konu uzmanları tarafindan değerlendirilmiş ve bir pilot uygulama ile ifadesel bazı düzenlemeler sonrasında örnek olarak belirlenen kütlede uygulamaya geçirilmiştir. Örgüt kültürü genelinde 3 alt bölümden oluşan anket 38 sorudan oluşmaktadır (İnovatif Düşünce Geliştirme-12 soru, İş Tatmini-15 soru, Örgüt Bağl1lığ-11 soru). Araştırma anketi 5' li likert ölçeği kapsamında uygulanmıştır. Bu ölçekler örgütsel davranış literatüründe yoğun bir şekilde kullanılmaktadır ve gerek davranışsal strateji gerekse davranışsal kamu yönetimi alanında son yıllarda araştırmacıların giderek daha çok ilgilerini çekmektedir [37].

Güvenilirlik analizi, bir ölçekte yer alan maddeler arasındaki iç tutarlılığ ölçer ve bu maddeler arasındaki ilişkiler hakkında bilgi sunar [39]. Nunnaly'e göre bir araştırmada elde edilecek olan 0,5 ve üstü Cronbach Alpha değeri çalışmanın güvenilirliği için yeterli olmaktadır [40, 41]. Yapılan çalışmada kullanılan ölçeklerin Cronbach Alpha katsayıları hesaplanmıştır. SPSS yardımıyla yapılan hesaplamada ölçek boyutunda Cronbach Alpha katsayısı 0,8697 olarak bulunmuştur. Bu sonuç ölçeğin güvenilirliğe sahip bir ölçme yaptığını ve değişkenlerin güvenli bir şekilde ölçümlendiğini göstermektedir.

Çalışmanın amacı doğrultusunda hipotezler geliştirilmiş ve alt üretim grupları düzeyinde farklılıkların belirlenebilmesi amacıyla istatistiksel analizler yapılmıştır (Tek Yönlü Varyans Analizi, Korelasyon Analizi ve Regresyon Analizi). Çalışmada istatistiksel analizler için SPSS (Statistical Package for Social Sciences) paket programı kullanılmıştır. Çalışma verileri değerlendirilirken parametrelerin normal dağılıma uygunluğu Kolmogorov-Smirnov testi ile değerlendirilmiştir. Çalışmada tanımlayıcı istatistiksel metotların (sayı ve yüzde) yanı sıra, niceliksel verilerde normal dağılım gösteren parametrelerin karşılaştırmalarında tek yönlü basit varyans analizi, niceliksel veriler arasındaki ilişkinin incelenmesi için pearson korelasyon analizi yöntemleri, ilişkisi olan değişkenlerin etki oranlarını görebilmek için ise çoklu doğrusal regresyon analizi yöntemleri kullanıldı. Sonuçlar $\% 95$ 'lik güven aralığında, anlamlılık $\mathrm{P}<0.05$ düzeyinde değerlendirilmiştir. 


\section{IV.SONUC}

Lif levha sanayi alanında faaliyet gösteren firmada yedi farklı bölümde 190 çalı̧̧an araştırma kapsamında yer almaktadır. Çalışanların bölümlerine göre dağılımları Tablo 1'de gösterilmektedir. Çalışanların 15'inin $(\% 7,9)$ elektrik bakımı, 39'unun $(\% 20,5)$ kaplama parke, 40'ının $(\% 21,1)$ kimya tesisleri, 16'sının $(\% 8,4)$ kalite kontrol, 8'inin $(\% 4,2)$ planlı bakım, 31'inin $(\% 16,3)$ mekanik bakım ve 41 'inin $(\% 21,6)$ MDF üretim bölümlerinde oldukları görülmektedir.

Tablo 1. Çalışanların bölümlerine göre dağıllımları

\begin{tabular}{lcc}
\hline Bölümler & Çalışan sayısı & $\begin{array}{c}\text { Dağılım } \\
(\%)\end{array}$ \\
\hline Elektrik bakım & 15 & 7,9 \\
Kaplama parke & 39 & 20,5 \\
Kimya tesisleri & 40 & 21,1 \\
Kalite kontrol & 16 & 8,4 \\
Planlı bakım & 8 & 4,2 \\
Mekanik bakım & 31 & 16,3 \\
Mdf üretim & 41 & 21,6 \\
\hline
\end{tabular}

Araştırma kapsamında yer alan parametrelere çalışanların verdikleri cevapların ortalama değerleri Tablo 2'de gösterilmektedir.

Tablo 2. Parametrelere göre değerler

\begin{tabular}{lccc}
\hline Parametreler & Soru Sayısı & Ortalama & Standart Sapma \\
\hline İnovatif Düşünce & 12 & 2,97 & 0,91 \\
İs Tatmini & 15 & 3,09 & 0,92 \\
Örgüt Bağl1lığ 1 & 11 & 3,49 & 0,87 \\
Örgüt Kültürü & 38 & 3,17 & 0,89 \\
\hline
\end{tabular}

Çalışanların anket sorularına verdikleri cevapların konusal dağılımları dikkate alınarak yapılan hesaplamalarda en yüksek ortalamaya örgüt bağlılığı alanında ulaş1lırken, en düşük ortalama inovatif düşünce geliştirme boyutunda oluşmuştur.

Lif levha sanayisinde çalışanların bölümlerine göre inovatif düşünce geliştirme, iş tatmini, örgüt bağlılığı ve örgüt kültürü ölçeklerinin verilen cevaplar kapsamında tek yönlü varyans analizi sonuçları Tablo 3'deki gibidir. Çalışanların bölümleri dikkate alınarak yapılan tek yönlü varyans sonuçlarına göre bölümler kapsamında tüm alt faktörler düzeyinde istatistiksel olarak anlamlı farklılıklar örgüt belirlenmiştir $(\mathrm{P}<0,05)$.

Farklılığın hangi alt bölümden kaynaklandığının belirlenmesi amacıyla yapılan Duncan testi sonuçlarına göre inovatif düşünce geliştirme alt faktörü bakımından kaplama parke ve mekanik bakım bölümünde çalışanların sahip oldukları düşük ortalama değerin etkili olduğu ve özellikle kalite kontrol bölümü çalışanlarının inovatif düşünce bakımından yüksek bir ortalama değer göstermesi farklılığın sebebi olarak görülmektedir $(\mathrm{P}<0,05)$.

Örgüt bağlılı̆̆ bakımından mekanik bakım bölümünde çalışanların sahip oldukları düşük ortama değer ve MDF üretim bölümünde çalışanlarının yüksek ortalama değerleri istatistiksel farklılığın nedeni olarak belirlenmiştir. $(\mathrm{P}<0,05)$. Örgüt bağlılı̆̆ konusunda özellikle firmanın ana üretim konusunu oluşturan MDF üretim hattı çalışanlarının verdikleri cevapların en yüksek ortalamaya sahip olması oldukça anlamlı bir sonuç olarak değerlendirilmiştir. İş tatmini ve örgüt kültürü faktörleri de bölümlere göre istatistiksel olarak anlamlı bir farkl11ı göstermektedir $(\mathrm{P}<0,05)$. Ancak yapılan Duncan testi sonucunda bölümler arasında bir gruplandırma oluşmamıştır. 
Tablo 3. Çalışanların bölümlerine göre tek yönlü varyans analizi sonuçları

\begin{tabular}{|c|c|c|c|c|c|c|}
\hline Faktörler & Bölümler & Sayı & Ortalama & $\begin{array}{c}\text { Standart } \\
\text { Sapma }\end{array}$ & $\mathbf{F}$ & $\mathbf{P}$ \\
\hline \multirow{8}{*}{$\begin{array}{l}\text { İnovatif Düşünce } \\
\text { Geliştirme }\end{array}$} & Elektrik Bakım & 15 & 3,1333 & 0,84680 & \multirow{8}{*}{2,426} & \multirow{8}{*}{$0,028^{*}$} \\
\hline & Kaplama Parke & 39 & 2,6421 & 0,93560 & & \\
\hline & Kimya Tesisleri & 40 & 3,2086 & 0,98414 & & \\
\hline & Kalite Kontrol & 16 & 3,2951 & 0,65419 & & \\
\hline & Planlı Bakım & 8 & 3,0021 & 0,68692 & & \\
\hline & Mekanik Bakım & 31 & 2,6828 & 0,88543 & & \\
\hline & MDF Üretim & 41 & 3,0779 & 0,88820 & & \\
\hline & Toplam & 190 & 2,9710 & 0,91280 & & \\
\hline \multirow{8}{*}{ İş Tatmini } & Elektrik Bakım & 15 & 3,1605 & 0,87167 & \multirow{8}{*}{2,509} & \multirow{8}{*}{$0,023 *$} \\
\hline & Kaplama Parke & 39 & 2,7778 & 0,99828 & & \\
\hline & Kimya Tesisleri & 40 & 3,2849 & 0,92171 & & \\
\hline & Kalite Kontrol & 16 & 3,3807 & 0,72892 & & \\
\hline & Planlı Bakım & 8 & 3,1321 & 0,69353 & & \\
\hline & Mekanik Bakım & 31 & 2,7627 & 0,95028 & & \\
\hline & MDF Üretim & 41 & 3,3085 & 0,81058 & & \\
\hline & Toplam & 190 & 3,0925 & 0,91544 & & \\
\hline \multirow{8}{*}{ Örgüt Bağl1lı̆ğ } & Elektrik Bakım & 15 & 3,5178 & 0,67877 & \multirow{8}{*}{2,461} & \multirow{8}{*}{$0,026^{*}$} \\
\hline & Kaplama Parke & 39 & 3,3175 & 0,90803 & & \\
\hline & Kimya Tesisleri & 40 & 3,6709 & 0,76773 & & \\
\hline & Kalite Kontrol & 16 & 3,6477 & 0,69937 & & \\
\hline & Planlı Bakım & 8 & 3,3682 & 0,66923 & & \\
\hline & Mekanik Bakım & 31 & 3,0867 & 1,05877 & & \\
\hline & MDF Üretim & 41 & 3,7474 & 0,84322 & & \\
\hline & Toplam & 190 & 3,4928 & 0,87307 & & \\
\hline \multirow{8}{*}{ Örgüt Kültürü } & Elektrik Bakım & 15 & 3,2572 & 0,80154 & \multirow{8}{*}{2,444} & \multirow{8}{*}{$0,027^{*}$} \\
\hline & Kaplama Parke & 39 & 2,8868 & 0,95138 & & \\
\hline & Kimya Tesisleri & 40 & 3,3742 & 0,89043 & & \\
\hline & Kalite Kontrol & 16 & 3,4326 & 0,68849 & & \\
\hline & Planlı Bakım & 8 & 3,1599 & 0,67576 & & \\
\hline & Mekanik Bakım & 31 & 2,8313 & 0,95636 & & \\
\hline & MDF Üretim & 41 & 3,3685 & 0,82954 & & \\
\hline & Toplam & 190 & 3,1710 & 0,89315 & & \\
\hline
\end{tabular}

Katılımcıların verdikleri cevaplara göre inovatif düşünce geliştirme, iş tatmini, örgüt bağlılığ ve örgüt kültürü arasında oluşan korelasyon düzeyi belirlenmiş ve sonuçlar Tablo 4'de verilmiştir.

Tablo 4. Örgüt bağglılı̆̆l, inovatif düşünce, iş tatmini ve örgüt bağglılı̆̆l ilişkisi

\begin{tabular}{|c|c|c|c|c|c|}
\hline & & İnovatif Düșünce & İş Tatmini & Örgüt Bağlılığı & Örgüt Kültürüi \\
\hline \multirow{2}{*}{ İnovatif Düşünce } & $\mathrm{r}$ & & $0,987 * *$ & $0,964 * *$ & $0,993 * *$ \\
\hline & $\mathrm{P}$ & 1 & 0,000 & 0,000 & 0,000 \\
\hline \multirow{2}{*}{ İş Tatmini } & $\mathrm{r}$ & $0,987 * *$ & \multirow{2}{*}{1} & $0,969 * *$ & $0,996 * *$ \\
\hline & $\mathrm{P}$ & 0,000 & & 0,000 & 0,000 \\
\hline \multirow{2}{*}{ Örgüt Bağ $\operatorname{lll}_{\text {Ĭğ} 1}$} & $\mathrm{r}$ & $0,964 * *$ & $0,969 * *$ & \multirow[b]{2}{*}{1} & $0,984 * *$ \\
\hline & $\mathrm{P}$ & 0,000 & 0,000 & & 0,000 \\
\hline \multirow{2}{*}{ Örgüt Kültürü } & $\mathrm{r}$ & $0,993 * *$ & $0,996^{* *}$ & $0,984 * *$ & \multirow{2}{*}{1} \\
\hline & $\mathrm{P}$ & 0.000 & 0.000 & 0.000 & \\
\hline
\end{tabular}

İnovatif düşünce geliştirme, iş tatmini, örgüt bağl1lı̆g ve örgüt kültürü ölçeklerinin ilişkilerinin incelenmesine ilişkin yapılan korelasyon analizi sonucunda bütün faktörler arasında istatistiksel olarak 
anlamlı bir ilişki tespit edilmiştir $(\mathrm{P}<0,05)$. Tüm ilişkiler pozitif yönlü ve çok kuvvetli ilişkilerdir. Örgüt kültürü puanlarına inovatif düşünce geliştirme, iş tatmini ve örgüt bağımlılığı puanlarının etkisine yönelik çoklu doğrusal regresyon analizine dair bulgular aşağıda verilen Tablo 5'de gösterilmektedir.

Tablo 5. Örgüt kültürü, inovatif düşünce, iş tatmini ve örgüt bağlllı̆̆l regresyon analizi

\begin{tabular}{lccccc}
\hline Değişkenler & B & $\begin{array}{c}\text { Standart } \\
\text { Hata }\end{array}$ & $\boldsymbol{\beta}$ & $\mathbf{t}$ & $\mathbf{P}$ \\
\hline Sabit & 0,008 & 0,003 & & 2,825 & 0,005 \\
İnovatif düşünce & 0,300 & 0,004 & 0,306 & 73,731 & 0,000 \\
İş tatmini & 0,414 & 0,004 & 0,424 & 94,906 & 0,000 \\
Örgüt bağl1lığ1 & 0,284 & 0,003 & 0,278 & 102,205 & 0,000 \\
\hline $\mathrm{R}=1,000 \quad$ Düzeltilmiş $\mathrm{R}^{2}=1,000$ & $\mathrm{~F}_{(3,186)}=762382,379$ & & $\mathrm{P}=0,000 * *$ \\
\hline
\end{tabular}

Lif levha sanayisinde çalışanlara uygulanan örgüt kültürü ölçeğine alt ölçekleri olan inovatif düşünce geliştirme, iş tatmini ve örgüt bağımlılığ ölçeklerinin etkisi olup olmadığına ilişkin çoklu doğrusal regresyon analizi sonuçları verilmiştir. Buna göre örgüt kültürü ölçeğinden alınan puanlar üzerinde, inovatif düşünce geliştirme, iş tatmini ve örgüt bağl1lığı puanlarının etkisi olduğu belirlenmiştir $\left(\mathrm{F}_{(3,186)}\right.$ $=762382,379 ; \mathrm{P}<0,05)$. Örgüt kültürü ölçeğinden alınan puanlara, inovatif düşünce geliştirme, iş tatmini ve örgüt bağlılı̆̆ puanları \%100 etki yapmaktadır. Aynı zamanda bütün bağımsız değişkenler istatistiksel olarak anlamlı bulunmuştur $(\mathrm{P}<0,05)$.

Lif levha sanayi alanında yedi farklı üretim bölümünde çalışan 190 kişi ile yapılan çalışma sonucunda inovatif düşünce geliştirme, iş tatmini, örgütsel bağlllık ve örgüt kültürü düzeyinde istatistiksel olarak anlamlı ve güçlü ilişkiler belirlenmiştir. Çalışanların cevapları dikkate alındığında kurumsal bir yapıya ve işleyen yazılı kuralar bütününe sahip olan firma çalışanlarında yüksek bir beğeni ve bağlılık duygusu oluşturmuştur. Kurumun toplumsal düzeyde sahip olduğu prestij çalışanları mutlu etmekte ve özellikle uygulamakta olduğu öneri sistemi tüm çalışanlarda sürekli yenilik ve inovatif düşünce geliştirmeye yönelik değerlendirmeler yapmaya teşvik etmektedir. Diğer bölümlere göre daha aktif bir çalışma ortamına sahip olan MDF üretimi ve kalite kontrol bölümleri çalışanları bu alanda ön planda olmaları dikkat çeken bir diğer dikkat çeken sonuç niteliğindir. Sektörümüz açısından olumlu bir yapıya sahip olan firma çalışanların memnuniyeti ve inovatif düşünceyi bir arada tutabilme başarısını göstermiştir. Tüm alt faktörlerin yüksek bir ilişki düzeyinde olması çalışanlara değer ve sorumluluk verilmesi ile inovatif düşünce ve bağll1ık duygusundaki artışın verimlilik ve rekabet üstünlüğünü sağlayacak olduğunu göstermektedir.

\section{KAYNAKLAR}

[1] B.Ç. Bayhan, "Lojistik işletmelerinde yenilik yönetimi ile yenilikçi örgüt kültürü ilişkisi," Yüksek Lisans tezi, Uluslararası Ticaret ve Lojistik Bölümü, Mersin Üniversitesi, Mersin, Türkiye, 2018.

[2] S.J. Hogan and L.V. Coote, "Organizational culture, innovation, and performance: A test of Schein's model,” Journal of Business Research, vol. 67, no. 8, pp. 1609-1621, 2014.

[3] N. Güçlü, “Örgüt kültürü,” Kırgızistan Manas Üniversitesi Sosyal Bilimler Dergisi, c. 6, ss. 147-159, 2003.

[4] H. Serin, M. Durgun ve S. Durgun, "James g. march: yönetim ve örgüt çalışmalarında örnek bir figür," Sosyal, Beşeri ve İdari Bilimler Alanında Yeni Ufuklar, Ankara, Türkiye: Gece Kitaplığı, 2019, böl. 2, ss. 29-50. 
[5] İ. Akyüz, U. Saraç ve N. Ersen, "Örgütsel davranış boyutları ile örgüt kültürü arasındaki ilişki: Ahşap panel levha sektörü örneği,” Bartın Orman Fakültesi Dergisi, c. 21, s. 3, ss. 793-802, 2019.

[6] E.H. Schein, Organizational Culture and Leadership, USA: Jossey-Bass, 2004.

[7] H. Serin ve M. Durgun, "İşletmelerde yenilikçi yaklaşım olarak stratejik yönetim süreci," Ziraat, Orman ve Su Ürünleri Alanında Yenilikçi Yaklaşımlar, Ankara, Türkiye: Gece Kitaplığı, 2018, böl. 3, ss. 23-42.

[8] M. Durgun, H. Serin ve Y Şahin, "Strategic management process at furniture firms," SelçukTeknik Dergisi, c. 14, s. 2, ss. 344-349, 2015.

[9] M. Alvesson, Understanding Organizational Culture, London, UK: Sage Publications, 2004.

[10] S. Davis, Managing Corporate Culture. 1st ed., Cambridge, UK: Ballinger Publishing, 1984.

[11] C. Uzkurt ve A.E. Demirci, Yenilik Yönetimi, Eskişehir, Türkiye: Anadolu Üniversitesi, 2012.

[12] P.F. Drucker, The Discipline of Innovation, UK: Harvard Business Review, 2002.

[13] H.K. Güleş ve H. Bülbül, Yenilikçilik, İşletmeler için Stratejik Rekabet Aracı, Ankara, Türkiye: Nobel Basım Yayın, 2004.

[14] H. Serin, M. Durgun ve S. Durgun, "Orman ürünleri sanayindeki davranışsal strateji çalışmaları üzerine bir derleme," Düzce Üniversitesi Bilim ve Teknoloji Dergisi, c. 8, s. 1, ss. 1002$1019,2020$.

[15] R.K. Jain, H.C. Triandis and C.W. Weick, Managing Research, Development and Innovation: Managing the Unmanageable, New Jersey, USA: John Wiley \& Sons, 2010.

[16] A, Barker, Yenilikçiliğin Simyası, İstanbul, Türkiye: Mess Yayın, 2002.

[17] F.P. Drucker, Innovation and Entrepreneurship, New York, USA: Harper \& Row Publishers Inc., 1999.

[18] B.S. Oğuztürk ve M. Türkoğlu, "Yenilik ve yenilik modelleri," Doğu Anadolu Bölgesi Araştırmaları, ss. 14-20, 2004.

[19] F.N. Yorgancılar, "Sürdürülebilir rekabet anlayışı olarak yenilik yeteneği," Selçuk Üniversitesi IIIBF Sosyal ve Ekonomik Araştırmalar Dergisi, c. 15, s. 21, ss. 379-425, 2011.

[20] N. Işık ve A. Kılınç, "İnovasyon-temelli ekonomi: seçilmiş ülkeler üzerine bir uygulama," Anadolu Üniversitesi Sosyal Bilimler Dergisi, c. 16, s. 1, ss. 13-27, 2016.

[21] O. Erdil, H. Keskin, S.Z. İmamoğlu ve S. Erat, "Yönetim tarzı ve çalışma koşulları, arkadaşlık ortamı ve takdir edilme duygusu ile iş tatmini arasındaki ilişkiler: Tekstil sektöründe bir uygulama," Doğuş Üniversitesi Dergisi, c. 5, s. 1, ss. 17-26, 2004.

[22] H.G. Çekmecelioğlu, "Örgüt ikliminin iş tatmini ve işten ayrılma niyeti üzerindeki etkisi: Bir araştırma," Dokuz Eylül Üniversitesi Sosyal Bilimler Enstitüsü Dergisi, c. 9, s. 1, ss. 79-97, 2007.

[23] Ö.Ç. Titizoğlu, "Etkileşimi ve dönüşümcü liderlik tarzlarının örgütsel özdeşleşme ve iş tatmini üzerine etkisi: Bir saha araştırması", Yüksek Lisans tezi, İşletme Bölümü, Abant İzzet Baysal Üniversitesi, Bolu, Türkiye, 2011. 
[24] H. Gürkan, C. Barut, O. Ünsel ve E. Aybay, "Demografik değişkenler ile iş tatmini arasındaki ilişkinin incelenmesi: Bitlis ili turizm sektörü çalışanları uygulaması," Bitlis Eren Üniversitesi Sosyal Bilimler Enstitüsü Dergisi, c. 6, s. 2, ss. 130-157, 2017.

[25] Z. Akıncı, "Turizm sektöründe işgören iş tatminini etkileyen faktörler: Beş yıldızlı konaklama işletmelerinde bir uygulama," Akdeniz Üniversitesi İ.I.B.F Dergisi, c. 4, ss. 1-25, 2002.

[26] İ. Akyüz, K. C. Akyüz, N. Ersen and M. Beker, "A research on the customer relationship management in the furniture and other forest products business (Istanbul provincial sample),"

Kastamonu Üniversitesi Orman Fakültesi Dergisi, vol. 17, no. 1, pp. 88-98, 2017.

[27] M.K. Abouraia and S.M. Othman, "Transformational leadership, job satisfaction, organizational commitment, and turnover intentions: the direct effects among bank representatives," American Journal of Industrial and Business Management, vol. 7, pp. 404-423, 2017.

[28] E. Nergiz ve F. Yılmaz, "Çalışanların iş tatmininin performanslarına etkisi: Atatürk Havalimanı Gümrüksüz Satış İşletmesi örneği," Kastamonu Üniversitesi İktisadi ve İdari Bilimler Fakültesi Dergisi, s. 14, ss. 50-79, 2016.

[29] T. Gedik, K.C. Akyuz and C. Batu, "Determination of manager job satisfaction level in forest products industry (The case of Duzce)," Kastamonu Üniversitesi Orman Fakültesi Dergisi, vol. 9, no. 1, pp. 1-11, 2009.

[30] M.Ö. Çetin, Örgüt Kültürü ve Örgütsel Bă̆lllık, Ankara, Türkiye: Nobel Yayın Dağıtım, 2004.

[31] S. G. Ar1, "Yöneticiye duyulan güven örgütsel bağl1lığı artırır mı?," Gazi Üniversitesi Ticaret Turizm Eğitim Fakültesi Dergisi, s. 2, ss. 17-36, 2003.

[32] R. Balay, Yönetici ve Ögrretmenlerde Örgütsel Băglllık, Ankara, Türkiye: Nobel Yayın Dağıtım, 2000.

[33] S. Tayyah and N. Tariq, "Development of an indigenous organizational commitment questionnaire," Pakistan Journal of Psychological Research-ProQuest Psychology Journals, vol. 16, no. $1 / 2$, pp. $31-44,2001$.

[34] Y. Wiener, "Commitment in organization a normative view," Academy of Management Review, vol. 7, no. 3, pp. 418-428, 1982.

[35] A.E.Reichers, "A review and reconceptualization of organizational commitment," Academy of Management Review, vol. 10, no. 3, pp. 465-476, 1985.

[36] A.C. Baysal ve M. Paksoy, "Mesleğe ve örgüte bağl1lığın çok yönlü incelenmesinde MeyerAllen modeli," İ. Ü Işsletme Fakültesi Dergisi, c. 28, s. 1, ss. 7-15, 1999.

[37] F. Luthans, Organizational Behavior, UK: McGraw-Hill, 1992.

[38] B. Toker, "Demografik değişkenlerin iş tatminine etkileri: İzmir'deki beş ve dört yıldızlı otellere yönelik bir uygulama," Doğuş Üniversitesi Dergisi, c. 8, s. 1, ss. 92-107, 2007.

[39] K. Ardıç ve T. Baş, "Kamu ve vakıf üniversitelerindeki akademik personelin iş tatmin düzeylerinin karşılaştırılması," 9.Ulusal Yönetim Organizasyon Kongresi'nde sunuldu, İstanbul, 2001. 
[40] N. Ersen, İ. Akyüz and B.Ç. Bayram, "The forecasting of the exports and imports of paper and paper products in Turkey using Box-Jenkins Method," Eurasian Journal of Forest Science, vol. 7, no. 1, pp. 54-65, 2019.

[41] A. H. Aydın, S. Durgun ve M. Durgun, "Davranışsal kamu yönetimi: yöntemsel ve teorik düzlemlerde bir inceleme,” J. Acad. Value Stud., c. 5, s. 4, ss. 528-542, 2019. 